\title{
British Journal for the History of Philosophy
}

\section{Kant on the original synthesis of understanding and sensibility}

\author{
Jessica J. Williams
}

To cite this article: Jessica J. Williams (2018) Kant on the original synthesis of understanding and sensibility, British Journal for the History of Philosophy, 26:1, 66-86, DOI: 10.1080/09608788.2017.1334189

To link to this article: https://doi.org/10.1080/09608788.2017.1334189

$$
\text { 曲 Published online: } 03 \text { Jul } 2017 .
$$

Submit your article to this journal

LIII Article views: 112

Q View related articles $₫$

View Crossmark data $\nearrow$ 


\title{
Kant on the original synthesis of understanding and sensibility
}

\author{
Jessica J. Williams \\ Department of Philosophy, University of South Florida, Tampa, FL, USA
}

\begin{abstract}
In this paper, I propose a novel interpretation of the role of the understanding in generating the unity of space and time. On the account I propose, we must distinguish between the unity that belongs to determinate spaces and times - which is a result of category-guided synthesis and which is Kant's primary focus in $\$ 26$ of the B-Deduction, including the famous B160-1n - and the unity that belongs to space and time themselves as all-encompassing structures. Non-conceptualist readers of Kant have argued that this latter unity cannot be the product of categorial synthesis. While they are correct that this unity is not the product of any particular act of category-guided synthesis, I argue that conceptualists are right to nevertheless attribute this unity to the understanding. I argue that it is a result of what we can think of as the 'original' synthesis of understanding and sensibility themselves - it is a synthesis, moreover, in which the whole is logically prior to the parts.
\end{abstract}

ARTICLE HISTORY Received 17 July 2016; Revised 24 January and 24 April 2017; Accepted 21 May 2017

KEYWORDS Kant; space; formal intuition; B-Deduction; conceptualism; non-conceptualism

\section{Introduction}

In a footnote to $\$ 26$ of the B-Deduction, Kant draws a distinction between space and time considered as forms of intuition, which he characterizes in terms of 'merely' providing a manifold, and as formal intuitions, which are distinguished from mere forms insofar as they involve 'unity of representation' (B160-1n). ${ }^{1}$ Kant offers the following account of this unity:

In the Aesthetic I ascribed this unity merely to sensibility, only in order to note that it precedes all concepts, though to be sure it presupposes a synthesis, which does not belong to the senses but through which all concepts of space and time first become possible. For since through it (as the understanding determines the sensibility) space or time are first given as intuitions, the unity of this a priori

CONTACT Jessica J. Williams 0 jjwilli7@gmail.com Department of Philosophy, University of South Florida, Tampa, FL 33620-9951, USA

'References to the Critique of Pure Reason utilize the standard format of ' $A$ ' and/or ' $B$ ' to refer to the first and/or second edition. References to Kant's other works are given by volume and page number of the Akademie edition. Translations are from the Cambridge Edition of the Works of Immanuel Kant. 
intuition belongs to space and time, and not to the concept of the understanding (§24).

(B160-1n, emphasis in the original)

This account has been described as 'infamous' (Kitcher, 'Connecting Intuitions'; Messina, 'Kant on the Unity of Space'), as having the 'appearance of a paradox' (Friedman, 'Space and Geometry'), as 'apparently contradictory' (Onof and Schulting, 'Space as Form of Intuition'), and 'so obscure that it can be made to serve the needs of any interpretation whatsoever' (Falkenstein, Kant's Intuitionism) by those who have nevertheless offered important interpretations of it. The reason for such descriptions is that Kant appears both to affirm and deny that the understanding plays a role in generating the unity of space and time as formal intuitions. If this were nothing more than a confusing footnote, it might be tempting to dismiss it - why not think Kant simply contradicts himself in a minor passage - but this is not an option. Understanding the footnote is key both to Kant's argument in the B-Deduction and his account of the nature of space and time. Furthermore, the apparent contradiction reflects a larger tension - between Kant's commitment to the fundamental duality of the faculties of sensibility and understanding and his commitment to the idea that these faculties nevertheless must be unified if they are to produce cognition - that must be resolved in any adequate interpretation of the critical philosophy.

Given this deep-seated tension, it should come as no surprise that there are important considerations in favour of each of the positions Kant seems to take in the footnote, and interpreters have largely been divided by which set of considerations they prioritize. Standard conceptualist interpreters are keen to emphasize that the argument of the Deduction depends on establishing that the unity of space and time must be informed by the categories. According to the Standard conceptualist reading of the footnote, the understanding is responsible for generating the unity of space and time as formal intuitions via acts of synthesis that are governed by the categories. ${ }^{2}$ This, in turn, is meant to guarantee that any object that can come before our senses will be subject to the categories, because any such object can only appear within the formal structures of space and time. A growing number of interpreters, on the other hand, have appealed to Kant's characterization of space as an infinite, all-encompassing whole that precedes its parts to argue that the unity of

\footnotetext{
${ }^{2}$ Versions of this interpretation can be found in Hegel, Faith and Knowledge; Paton, Kant's Metaphysics of Experience; Henrich, 'The Proof-Structure of Kant's Transcendental'; McDowell, Having the World in View; Bauer, 'A Peculiar Intuition' and Griffith 'Perception and the Categories'. Waxman, Kant's Model of the Mind; Keller, Kant and the Demands; Longuenesse, Kant and the Capacity; Gomes, 'Is Kant's Transcendental Deduction'; and Friedman, 'Kant on Geometry', 'Space and Geometry' depart from Standard Conceptualism in arguing that a pre-categorial synthesis is responsible for the unity of space.
} 
space cannot be a product of categorial synthesis, which has a part-whole priority. ${ }^{3}$ Some have even argued that space has an independent unity that does not depend on the understanding and is thus essentially non-conceptual (Onof and Schulting, 'Space as Form of Intuition'; McLear, 'Two Kinds of Unity'). Although the focus has been on space, the same considerations apply to time as an infinite given magnitude that precedes its parts.

In what follows, I propose an interpretation of the unity of space and time that accommodates the concerns raised by critics of the standard conceptualist reading, but without jettisoning its core commitment, which is that the unity of space and time can only be realized in conjunction with the unity of apperception and its conditions (the categories). On my view, the original synthetic unity of apperception (OSUA) involves the holistic consciousness of all the manifold of sensibility as belonging to the thinking subject. It is via this consciousness that space and time are given to the subject as unified structures (i.e. as formal intuitions). While this consciousness requires that the subject undertake the never-ending task of determining the empirical manifold through category-guided figurative synthesis, it cannot be reduced to any particular act of category-guided synthesis. The structure of the paper is as follows. In $\$ 2,1$ present the Standard Conceptualist interpretation of the unity of space and time and the criticisms of this view, many of which also apply to so-called 'Broad' conceptualist views. In $\$ 3$, I present my account of the way in which the holistic consciousness that arises from the synthesis of understanding and sensibility - that is, the realization or instantiation of the OSUA in relation to the manifold of human sensibility - accounts for the fact that space and time are given to the thinking subject as unified structures. Finally, in $\S 4$, I explain the advantages of this view over its non-conceptualist rivals.

\section{The standard conceptualist reading and its critics}

Kant's goal in the Transcendental Deduction is to establish the objective validity of the categories. Since the publication of Dieter Henrich's ('The ProofStructure of Kant's Transcendental') paper on the proof-structure of the BDeduction, commentators largely have agreed that Kant's argument is divided into two steps, even if they disagree about what constitutes each step. ${ }^{4}$ Kant indicates that 'the beginning of a deduction' can be found in the following proposition, which sums up the argument of §§15-20:

A manifold that is contained in an intuition that I call mine is represented as belonging to the necessary unity of self-consciousness through the synthesis

\footnotetext{
${ }^{3}$ See Keller, Kant and the Demands; Longuenesse, Kant and the Capacity; Friedman, 'Kant on Geometry', 'Space and Geometry'; McLear, 'Two Kinds of Unity', Messina, 'Kant on the Unity of Space'; Smyth, 'Infinity and Givenness'; and Onof and Schulting, 'Space as Form of Intuition'.

${ }^{4}$ Henrich, 'The Proof-Structure of Kant's Transcendental' argues that the first step concerns intuitions that already have unity, while the second step lifts this restriction. See Allison, Kant's Transcendental Idealism, 159-63 and Gomes, 'Is Kant's Transcendental Deduction' for alternatives accounts of the two steps.
} 
of the understanding and this takes place by means of the category.

(B144, emphasis in the original)

As Kant's summary indicates, the first step of the Deduction concerns the conditions of representation that stem from the nature of the understanding. Very roughly, we can reconstruct Kant's argument as follows. The representation of an object in thought involves the unification of representations (B130). Representations can only be unified insofar as they belong to a single consciousness (B137). Because the ' $\mathrm{I}$ ' is a simple representation (B135), its unity (the analytic unity of apperception) can only be explained by appeal to the unity of the acts of synthesis through which it combines representations (the synthetic unity of apperception). The categories are precisely the rules for the synthesis of representations with each other in a single consciousness. Thus, 'all sensible intuitions stand under the categories, as conditions under which alone their manifold can come together in one consciousness' (B143). In other words, Kant argues that the analytic unity of apperception is a basic requirement for discursive thought and this requirement can only be met if the manifold of intuition is combined according to the categories.

Kant claims that the first step, although it concerns the manifold of an intuition in general, 'abstracts from the way in which empirical intuition is given' (B144). It is in the second step of the argument, which culminates in \$26, that Kant turns his attention to the way in which empirical intuitions are given in sensibility. A central premise in the second step is that space and time are represented a priori not only as forms of intuition but also as 'intuitions themselves (which contain a manifold)' and thus depend on the categories for the determination of the manifold they contain (B160-1).

The footnote, which I now quote in full, is appended to Kant's claim that space and time are represented as 'intuitions themselves':

Space, represented as object (as is really required in geometry), contains more than the mere form of intuition, namely the comprehension of the manifold given in accordance with the form of sensibility in an intuitive representation, so that the form of intuition merely gives the manifold, but the formal intuition gives unity of the representation. In the Aesthetic I ascribed this unity merely to sensibility, only in order to note that it precedes all concepts, though to be sure it presupposes a synthesis, which does not belong to the senses but through which all concepts of space and time first become possible. For since through it (as the understanding determines the sensibility) space or time are first given as intuitions, the unity of this a priori intuition belongs to space and time, and not to the concept of the understanding (\$24).

(B160-1n, emphasis in the original)

On the Standard Conceptualist interpretation, space as a formal intuition is identified with space as an all-encompassing whole that includes every spatial intuition (and the formal intuition of time is likewise the whole of time that includes every temporal intuition). The unity of space and time as 
formal intuitions depends on acts of category-guided synthesis. ${ }^{5}$ If we combine this with the premise that any object can come before our senses will be in space and time (one of the results of the Transcendental Aesthetic) we get the conclusion that any object that can come before our senses will be subject to the categories. Dieter Henrich offers a clear statement of this interpretation when he writes:

Wherever we find unity, this unity is itself made possible by the categories and determined in relation to them. In our representations of space and time, however, we have intuitions which contain unity and which at the same time include everything that can be present to our senses.

(Henrich, 'The Proof-Structure of Kant's Transcendental', 646)

The Standard Conceptualist reconstruction of Kant's argument in §26, socalled because it attributes the unity of space and time as formal intuitions to the application of categories (pure concepts), aims at an important result, namely an explanation of why the categories will apply to any object that can come before the senses.

An important question that arises at this point is why Kant needs the second step of the Deduction. Does not it follow from the first step, after all, that for anything to have the unity that constitutes the representation of an object, it must stand under the unity of apperception and thus the categories? The second step is not, however, merely an instantiation of the first step. Kant claims that the goal of the second step is to show from 'the way in which the empirical intuition is given in sensibility that its unity can be none other than the one the category prescribes to the manifold of a given intuition in general' (B144-5). The first step, precisely because it concerns the conditions for thought, leaves open the nature of the objects qua objects of sensibility. ${ }^{6}$ In other words, we can grant that we are forced to think of objects in a certain way in order to have thought at all - but this is merely a claim about how we are constrained to think. As Anil Gomes ('Is Kant's Transcendental Deduction') points out, the first step leaves Kant open to the kind of criticism of the Deduction levelled by James Van Cleve: the most Kant has shown is that 'we must apply the categories', not that the categories 'actually apply to objects of experience' (Van Cleve, Problems from Kant, 89; Gomes, 'Is Kant's Transcendental Deduction', 118). ${ }^{7}$

\footnotetext{
${ }^{5}$ For similar claims concerning the connection between the unity of space and categorial unity, see McDowell, Having the World in View, 74 and Bauer, 'A Peculiar Intuition'.

${ }^{6}$ As Hannah Ginsborg, 'Was Kant a Non-Conceptualist?', 70 emphasizes, Kant needs to show that the categories play a role in the perceptual apprehension of objects in order to successfully respond to the Humean objection that pure concepts do not legitimately apply to objects of experience. Van Cleve's worry, I take it, is a version of this Humean objection.

${ }^{7}$ Kant was aware of this kind of criticism as he was drafting the B-edition Deduction. Johann Schultz posed the following dilemma for Kant's 1781 deduction of the categories at the end of his 1785 review of a metaphysics textbook by J.A.H Ulrich. According to Schultz, if 'experience' refers to judgements of experience, the Humean sceptic can simply deny that we (legitimately) make this kind of judgement.
} 
Notice that a second step that involved a mere instantiation of the first step of the argument does not remove this worry. The second step must show that the categories are not just the necessary rules of the combination of representations in thought, but are exemplified by objects. As Kant himself notes in $\$ 22$, 'Things in space and time ... are only given insofar as they are perceptions (representations accompanied with sensation), hence through empirical representation' (B147, emphasis in the original). It is not enough to show that the categories are necessary rules for thought or even that they apply to a priori intuitions. For Kant to show that the categories are exemplified by objects, he must show that they apply to empirical intuitions. On the Standard Conceptualist reading of $\$ 26$, the argument proceeds by showing the way in which the apprehension of empirical intuitions (the synthesis of apprehension) in fact depends on the synthetic unity of space and time, which in turn, is only possible in relation to the categories. Although the matter of what is empirically given in no way depends on the understanding, the unity of space and time through which we empirically apprehend this matter depends on the understanding. Because nothing can be given as an object except in space and time, this means that anything that is an object of the senses must be in conformity with the categories. That is, the categories are not just laws of thought, but also laws of nature.

\subsection{Problems for the standard conceptualist reading}

Despite its relatively straightforward explanation of the argument of $\$ 26$, the Standard Conceptualist reading is not without its problems. Many of these problems are now well covered in recent literature (Messina, 'Kant on the Unity of Space'; McLear, 'Two Kinds of Unity'; Onof and Schulting, 'Space as Form of Intuition'). Since my goal is to give an interpretation of the unity of intuition that preserves the core commitments of the Standard Conceptualist account, but which addresses the problems raised in the recent literature, I will rehearse these criticisms before turning to my positive proposal, which I will do in $\S 3$.

An initial set of concerns arises from Kant's own puzzling claims within the B160-1n. First, although Kant claims that the synthesis that is presupposed by space and time does not belong to the senses, he also claims that it 'precedes all concepts'. If the synthesis responsible for the unity of space and time precedes even the categories, this is clearly a major problem for the Standard

If 'experience' refers to judgements of perception, this contradicts Kant's claim in the Prolegomena that such judgements do not require the categories (Sassen, Kant's Early Critics). We can thus take Kant's BDeduction to be in part concerned with the Humean worry Schultz raises. The way Kant addresses this kind of worry is by showing that the categories are conditions not just for thought of objects, but also for the perception of objects. I take it that Kant thinks that both steps of the Deduction are required to establish that we legitimately make judgements of experience. For further discussion of Kant's revisions in light of Schulz's criticism, see Pollok, "'An Almost Single Inference"'. 
Conceptualist reading. Second, Kant closes the footnote by claiming that the unity of space and time 'belongs to space and time, and not to the pure concept of the understanding'. Why would he ascribe this unity to sensibility in the Aesthetic and insist in the Deduction that it belongs to space and time if it is the result of conceptually guided synthesis by the understanding?

In addition to these textual concerns, recent critics of the Conceptualist reading have forcefully argued that the unity of space simply cannot be the product of synthesis. The unity at stake here is the unity of space and time as described in the Aesthetic, that is, as singular wholes that precede their parts (A25/ B39). Synthesis, as Kant defines it, is the action of gathering together, running through, and unifying the manifold 'into a certain content' (A77-8/ B103) and, at least as it is usually described, this is a process where one proceeds from given parts to produce a unified representation. Kant assigns the activity of synthesizing the manifold of sensible intuitions to the productive imagination. He distinguishes the synthesis carried out by the imagination, what he calls 'figurative synthesis', from the intellectual synthesis that is 'thought in the mere category in regard to the manifold of intuition in general' (B151). In other words, figurative synthesis is the form that categorial synthesis takes when it is applied to the manifold of human intuition. A priori figurative synthesis is directed at the pure forms of intuition (space and time) and yields the form of sensible experience that constrains the synthesis of apprehension that makes the perception of empirical objects possible. According to a number of critics (Messina, 'Kant on the Unity of Space'; McLear, 'Two Kinds of Unity'; Onof and Schulting, 'Space as Form of Intuition'), there are two aspects of category-guided figurative synthesis that make it unfit to be the source of the unity of space as described in the Aesthetic, which, it should be recalled, is precisely the unity that Standard Conceptualists take Kant to be concerned with in the B160-1n and surrounding text.

First, critics argue that the product of the figurative synthesis that is carried out on the manifold of intuition (pure or empirical) is always a determinate intuition, that is, an intuition of a part of space or time that has been assigned determinate properties (Messina, 'Kant on the Unity of Space'; McLear, 'Two Kinds of Unity'). For example, to represent a line as an object, one must generate the line through a successive synthesis of the parts that is guided by the consciousness that these parts belong together into a representational unity, where such consciousness is guided by the concept of a magnitude (A162/ B203). A line, like other determinate spatial intuitions, is an extensive magnitude, that is, a magnitude in which 'the representation of parts makes possible the representation of the whole' (A162/ B203). But the unity of space itself is the unity of a whole that precedes its parts.

Second, this mereological problem is amplified when considering that space is an infinite given magnitude. If the unity of space resulted from 
successive synthesis (in the way that the unity of an extensive magnitude does), this would mean 'our conception of space as an infinite whole would be logically constructed from our grasp of the discrete spaces composing it' (McLear, 'Two Kinds of Unity', 88). This kind of grasp of infinity is beyond the reach of finite discursive understandings. At most, successive synthesis is an indefinite process that can never yield an actual infinity. ${ }^{8}$ In short, although conceptually guided synthesis can explain the unity that belongs to the representation of a determinate space as an object (e.g. a line), it does not seem well suited to explain the unity that belongs to the whole of space itself.

Although I have presented Standard Conceptualism as the target of these criticisms, we must note that these criticisms are equally directed to the 'Broadly Conceptualist' accounts ${ }^{9}$ offered by Beatrice Longuenesse, Kant and the Capacity and Michael Friedman, 'Kant on Geometry'. Broadly Conceptualist views grant that categorial synthesis cannot explain the unity of space and time, but nevertheless attribute this unity to a pre-conceptual synthesis that stems directly from the unity of apperception.

Although their characterizations of the pre-conceptual synthesis responsible for the unity of space as a formal intuition differ, the accounts offered by Longuenesse and Friedman nevertheless suffer from the problems that plague Standard Conceptualist accounts. Critics claim that if this synthesis is an activity of running through and gathering together a manifold, it still has the problematic part-whole priority that poses a problem for conceptual synthesis, even if it takes place prior to the application of concepts (Messina, 'Kant on the Unity of Space', 21 and McLear, 'Two Kinds of Unity', 91). We can see this most clearly in Friedman's account, which appeals to an idealized procedure of continuous translation and rotation to explain the unity of space. ${ }^{10}$ Even idealized, this procedure, like any procedure of spatial construction, presupposes that space is already given as a whole; it thus cannot explain this unity. ${ }^{11}$ Furthermore, it is not clear in what sense this is a pre-conceptual synthesis, since the Euclidian constructions to which Friedman appeals

\footnotetext{
${ }^{8}$ See Messina, 'Kant on the Unity of Space'; McLear, 'Two Kinds of Unity'; Onof and Schulting, 'Space as Form of Intuition'. For an earlier criticism of synthesis along these lines, see Keller, Kant and the Demands. ${ }^{9}$ The terminology of 'Broad conceptualism' and 'Broad Non-Conceptualism' comes from Onof and Schulting, 'Space as Form of Intuition'.

${ }^{10}$ Friedman argues that space as the mere form of intuition provides a manifold of possible spatial perspectives, which are transformed by the unity of apperception into a single unitary space (which he identifies with space as a formal intuition) through the following idealized constructive procedure. A subject at a given point is in principle able to translate her perspective to another point through the drawing of a straight line, and from there, change her orientation by rotating around the point in a given plane. In this way, a manifold of possible perspectives is unified by the 'requirement that any such local perspective can be accessible to the same perceiving subject via (continuous) motion - via a (continuous) sequence of translations and rotations' - a requirement that stems directly from the transcendental unity of apperception and which explains the continuity of space and time. Friedman, 'Space and Geometry', 17-18. See also Friedman, 'Kant on Geometry', 247f.

${ }^{11}$ Onof and Schulting, 'Kant, Kästner, and the Distinction' have also criticized Friedman along these lines.
} 
presuppose the category of quantity. ${ }^{12}$ Things are more complicated in Longuenesse's case. In her more recent defense of her view, she claims that the unity of apperception, 'prior to any specific synthesis' accounts for the unity of space and time (Kant on the Human Standpoint, 36). While I think this is a promising line of response, she does not retract her earlier claim that space and time are 'products of the figurative synthesis of the imagination' (Kant and the Capacity, 216). The problem is that when Kant introduces figurative synthesis, he explicitly claims that it takes place 'in accordance with the categories' (B152). It is not clear how an appeal to figurative synthesis is in line with the insistence that the synthesis responsible for the unity of space and time is pre-conceptual, as Longuenesse and Friedman maintain. ${ }^{13}$ Moreover, as we have seen, critics argue that figurative synthesis concerns determinate intuitions and thus has a part-whole priority. It is thus not clear how figurative synthesis could explain the whole-part priority of space and time. ${ }^{14}$

At this point, one might be tempted to throw in the towel for the conceptualist and opt for a non-conceptualist account of the unity of space and time. On this kind of account, the unity of space and time as all-encompassing wholes is a 'brute given' of sensibility and in no way depends on the understanding. ${ }^{15}$ Since some non-conceptualists argue that conceptual determination of space and time is nevertheless required in order to bring this independent unity (unicity) under the transcendental unity of apperception and thus to cognize objects in space and time, this can seem like an appealing alternative, one that does not threaten Kant's argument in the Deduction. ${ }^{16}$ In the next section, I will argue that we do not need to throw in the towel just yet. And then I will explain the advantages of avoiding the non-conceptualist view.

\section{Original synthesis, figurative synthesis, and the B160-1n}

Critics of Conceptualism rely on the assumption that all acts of synthesis proceed from parts to whole and thus cannot explain the whole-part priority of space and time. The key to salvaging a conceptualist interpretation of the unity of intuition is to challenge the assumption that all synthesis has a part-

\footnotetext{
${ }^{12}$ In the Axioms of Intuition, Kant argues that the successive synthesis through which one generates a determinate space or time depends on the concept of a magnitude. See Sutherland, 'The Role of Magnitude' for more discussion of this point.

${ }^{13}$ See Longuenesse, Kant and the Capacity, 224. Friedman, 'Space and Geometry', fn. 25.

${ }^{14}$ Longuenesse talks of figurative syntheses (plural) taking place within the formal intuitions of space and time (Kant and the Capacity, 223), yet on her account the formal intuitions of space and time are supposed to be products of figurative synthesis. As Messina, 'Kant on the Unity of Space' notes, one option would be to distinguish two kinds of figurative synthesis. But if this is what Longuenesse has in mind, she does not make it clear. Furthermore, there is no textual evidence for a kind of figurative synthesis that does not involve the categories.

${ }^{15}$ Allison, Kant's Transcendental Idealism, McLear, 'Two Kinds of Unity', Onof and Schulting, 'Space as Form of Intuition'.

${ }^{16}$ Here I have in mind Allison, Kant's Transcendental Idealism and Onof and Schulting, 'Space as Form of Intuition'.
} 
whole priority. In this section, I argue that there is a holistic dimension to all acts of synthesis that stems directly from the OSUA. To explain the unity of space and time as formal intuitions - as the unified structures in which all acts of figurative synthesis take place - the conceptualist must distinguish particular acts of figurative synthesis, all of which are guided by the categories and result in determinate intuitions (i.e. intuitions of spaces and times, which are the form of empirical objects) - from the 'original synthesis' of space and time. At the same time, we must note that 'original synthesis' is not so much a different kind of synthesis as it is the holistic dimension of all synthesis in relation to the sensible manifold.

\subsection{Original synthesis}

The original synthesis of space and time, in virtue of which they are given to the subject as singular wholes, is the act of consciousness through which the subject grasps her own sensible nature as unified by her capacity to determine what is sensibly given. It can be fruitfully thought of, not as a synthesis or combination of parts, but as the synthesis of understanding and sensibility themselves, which grounds the identity of apperception and the unity of space and time. It is the realization, or instantiation, of the OSUA in relation to the manifold of human sensibility.

My appeal to original synthesis as the explanation of the unity of space and time is grounded primarily in §§15-17 of the B-Deduction. In these sections, Kant introduces the OSUA and argues that it is the 'highest principle' of the understanding. Here it will help to reconstruct Kant's account of the OSUA. We will then be able to see that the OSUA as realized in relation to our forms of sensibility involves the holistic consciousness of the necessary unity of space and time. As Standard Conceptualists have long insisted, the OSUA depends on the categories because it is only through categorial synthesis that the OSUA can be realized. Yet, we can take the following insight from Broad Conceptualism, namely that there is a global aspect of the OSUA that does not depend on any particular act of categorial synthesis. Rather than see this as something that is pre-conceptual or pre-categorial, however, we should understand this is as involving the consciousness that all the manifold of pure intuition is available to the subject in virtue of the subject's consciousness of her own capacity for affecting unity through ruleguided synthesis.

\subsubsection{The OSUA as the 'highest principle' of thought}

Thinking is the unification of representations, and, as such, involves a thinker, one who is doing the unifying. In order to combine multiple representations into a single unified representation (e.g. a thought), these representations must belong to the same thinker. Even the constituents of thoughts and 
judgements, concepts, are possible only insofar as 'the same consciousness is contained in many representations' (B136n). This sameness, or identity, of the thinking subject is not, however, given through the nature of self-consciousness (apperception) itself. The 'I' of apperception is simple; through it, 'nothing manifold is given' (B135). For Kant, this means that the identity of the thinking subject across representations - that the same consciousness belongs to each of these representations (the analytic unity of apperception) - depends on the unity of the action of synthesizing these representations together and the consciousness of this unity (the synthetic unity of apperception). Kant writes, 'I am therefore conscious of the identical self in regard to the manifold of the representations that are given to me in an intuition because I call them all my representations, that constitute one' (B 135, emphasis in the original). What it means to say that my representations 'constitute one' is that 'I am conscious a priori of their necessary synthesis' (B135).

\subsubsection{The OSUA and space and time}

The OSUA is a requirement for any discursive understanding, and as such, it is 'entirely independent from all conditions of sensible intuition' (B137). At the same time, precisely because discursive understandings are those that do not create the manifold but can only attain self-consciousness through the synthesis of a given manifold, the OSUA must be realized in relation to some manifold or other. ${ }^{17}$ In our case, that manifold is spatio-temporal. Kant's own example in $\$ 17$ of the OSUA involves the synthesis of the spatial manifold involved in the cognition of a line. Kant writes:

[I]n order to cognize something in space, e.g., a line, I must draw it, and thus synthetically bring about a determinate combination of the given manifold, so that the unity of this action is at the same time the unity of consciousness (in the concept of a line), and thereby is an object first cognized.

(B137-8, emphasis in the original)

The OSUA in this case is the consciousness of the unity of the action of synthesis that is expressed in the concept of a line.

We should note that this is an example of figurative synthesis, which, critics claim, always yields a determinate intuition. More generally, one could take Kant's point about the OSUA to be something that applies locally, in the

\footnotetext{
${ }^{17}$ It is often assumed that the first step of the Deduction concerns intellectual synthesis, while the second step concerns figurative synthesis. Admittedly, Kant is concerned in the first step with the unity that the categories as forms of thought confer on a given manifold, while in the second step, Kant is concerned with the details of how these forms relate to empirical intuition via the a priori figurative synthesis that governs the synthesis of apprehension. Nevertheless, already in the first step, Kant's discussion of the OSUA appeals to the specific form of human intuition (see B136n and B138) and thus, I take it, already to the way in which the intellectual synthesis is realized in relation to the a priori forms of human sensibility. The second step, then, concerns the way in which a priori figurative synthesis constrains the empirical synthesis of apprehension (which in turn establishes that the unity of empirical intuition can be 'none other' than the unity that the categories prescribe to intuition in general).
} 
sense that I cannot become conscious of the manifold of any given intuition without having an at least implicit consciousness of the way in which the manifold of this intuition constitutes a unity. But the OSUA must also involve the global consciousness of the unity of the entire manifold of sensibility. ${ }^{18}$ Textual support for this global aspect of OSUA can be found in Kant's statement that '[s]ynthetic unity of the manifold of intuitions, as given a priori, is thus the ground of the identity of apperception itself' (B134). Kant does not here seem to have in mind any local manifold of intuition, but, as he puts it in the A-Deduction, 'the entire sensibility, and with it also all possible appearances' (A111).

The deeper philosophical point here is that the kind of local unity of apperception involved in any particular act of synthesis is parasitic on a global unity of apperception. We can make this point with respect to the synthesis of concepts as well as with respect to the synthesis of intuitions. Concepts essentially involve generality, a point that Kant makes when he writes that:

a representation that is to be thought of as common to several must be regarded as belonging to those that in addition to it also have something different in themselves; consequently they must antecedently be conceived in synthetic unity with other (even if only possible representations) .... ${ }^{19}$

(B133n, emphasis in the original)

There must, in other words, be a global framework of representations in order for concepts, and thus local instances of unifying a manifold, to get off the ground. In the case of spatio-temporal intuitions, there is a similar dependence of the local on the global, in the sense that any determinate intuition is a delimitation of a larger space or time. These are not unrelated points. For Kant, a manifold of possible representations is available to the thinking subject precisely because she grasps the unity of her own sensible nature. We might even put the point by saying that self-consciousness entails grasping one's own sensible nature as subject to a necessary unity. ${ }^{20}$ This is captured in the principle of the OSUA, namely the principle that 'all the

\footnotetext{
${ }^{18} \mathrm{I}$ am of course not the first commentator to notice the global or holistic dimension of the OSUA. Brook, Kant and the Mind discusses this global aspect of representation at length. See also Newton, 'Kant on the Logical', 10.

${ }^{19}$ Gareth Evans formulates the generality constraint as follows: 'If we hold that the subject's understanding of " $\mathrm{Fa}$ " and his understanding of "Gb" are structured, we are committed to the view that the subject will also be able to understand the sentences "Fb" and "Ga"' (Varieties of Reference, 101). Evans is speaking here of sentences, but the point applies equally to thoughts. Kant's way of putting this point is that if red is serving as a concept of an object, $a$, (Ra), then it must be something that, as a mark, I can combine with other representations (as I do in $\mathrm{Rb}$; $\mathrm{Rc}$; Re), which, if they (b, c, e) are other representations, must also have something different in themselves.

${ }^{20}$ I thus fundamentally agree with Messina, 'Kant on the Unity of Space', who argues that it is a necessary property of the thinking subject that it possess a whole intuition that makes possible the synthesis of the manifold within it, as this is a condition of the acts of synthesis that underwrite the unity of apperception. On my view, the synthetic unity of space and time results from the synthesis of understanding and sensibility themselves. That is, it is via an act of spontaneity (self-consciousness) that space and time are given to the subject as unified structures.
} 
manifold of intuition stand[s] under conditions of the original synthetic unity of apperception' (B136). In a footnote to the principle, Kant writes:

Space and time and all their parts are intuitions, thus individual representations along with the manifold they contain in themselves (see the Transcendental Aesthetic), thus they are not mere concepts by means of which the same consciousness is contained in many representations, but rather are many representations that are contained in one and the consciousness of it; they are thus found to be composite, and consequently the unity of consciousness, as synthetic and yet as original, is to be found in them.

(B136n, emphasis in the original)

Space and time are not composites in the sense of being put together out of parts (we have already seen the reasons this cannot be so). They are composites, however, in the sense that that 'they are many representations that are contained in one', where being 'contained in one', for Kant, is a function of apperception. Thus, space and time are not concepts, but their unity, like that of concepts, depends on the unity of consciousness.

At this point, one might wonder how the synthetic unity of apperception can encompass an 'entire sensibility', especially since Kant thinks that the unity of apperception goes hand in hand with the unity of the action of synthesis, and there is no action of synthesis that encompasses infinite space and time. It is not through any particular action of synthesis that consciousness encompasses all of sensibility; instead, it is through the subject's consciousness of her own capacity to determine her sensible nature that the pure manifolds of space and time are given to the subject as singular wholes.

How can this capacity explain the unity of space and time as infinite? It will help to think here about what it means to say that an infinite space and time are available to the subject. We do not perceive an infinite space. Instead, to say that space is infinite, as Kant puts it in his comments on Kästner, is to say that the space in which I describe a line 'is greater than any which I might describe in it' (Allison, The Kant-Eberhard Controversy, 173). Any region of space is experienced as part of a larger space, without limit. We might ask, with Kant, how such an intuition is possible. Kant's answer, in a Reflexion dated between 1773 and 1775, is that space 'is nothing other than the consciousness of one's own receptivity for sensing representations (impressions) of things in accordance with certain relations among them' (R 4673 P. II, Ak 17:638, italics added). It is unitary, according to Kant, 'because it is the form of representations of all possible objects in a unitary subject' ( $\mathrm{R} 4673$ Ak 17: 641). And the subject is unitary because of her capacity for effecting unity through the spontaneity of apperception as expressed through the categories.

This allows us to adopt one very particular way of reading Michael Friedman's claim that the unity of infinite space is a result of the the requirement that any ... local [spatial] perspective must be accessible to the same perceiving subject via (continuous) motion - via a (continuous) sequence of 
translations and rotations' (17). We should place particularly strong emphasis on the word 'accessible' here. It is the subject's recognition of the possibility of accessing any part of boundless space in this way that is doing the work, not the procedures themselves. ${ }^{21}$

\subsubsection{The OSUA and the categories}

Here we come to the fundamental divide between Standard Conceptualists and Broad Conceptualists. The Broad Conceptualist traces the unity of space and time directly to the unity of apperception, but claims that this unity precedes any application of the categories and is thus pre-conceptual. The Standard Conceptualist will insist, however, that the unity of apperception is only expressed or manifested through categorial synthesis. Yet, as we have seen, no categorial synthesis can explain the unity of space and time themselves.

Kant's claim in $\$ 15$ that the categories presuppose a 'higher' unity that 'precedes all concepts of combination a priori' can be taken to support the Broad Conceptualist (B131). At the same time, in referring to this unity as 'qualitative' (in order to distinguish it from the category of unity) Kant refers the reader back to $§ 12$, where qualitative unity is 'the unity of the concept' through which the 'unity of the comprehension of the manifold of cognition is thought' (B114). This unity of comprehension - the ability to grasp diverse representations as constituting a unity - is what all concepts, including the categories, express. $^{22}$ It is in this sense that the OSUA is 'higher' than the categories. It is the most fundamental form of all conceptualization and judgement. And while it makes sense to talk about this fundamental capacity - the capacity for comprehension - in isolation from particular instances of its expression they are after all logically distinct from one another - we also cannot divorce this capacity from its expression. When it comes to explaining the unity of space and time themselves, we must not appeal to any particular act of categorial synthesis, but to the subject's consciousness of the capacity that the categories express; consciousness of this capacity in relation to sensibility is what explains the subject's holistic consciousness of her 'entire sensibility'.

\subsection{Original synthesis and figurative synthesis in the B160-1n}

Focusing on the holistic consciousness that characterizes the OSUA helps us to address the criticisms of conceptualism, which are largely directed at the

\footnotetext{
${ }^{21}$ We thus need not deny that the procedures themselves have a conceptual component (the unity of action of translation and rotation requires the ability to see one's action as general, where generality is the mark of the conceptual).

${ }^{22}$ Kant goes on to compare this unity to 'the unity of the theme in a play, speech, or a fable' (B114). I take it that one understands the way in which the parts of a play, speech, or a fable fit together by having a prior sense of the theme that unifies them. One's grasp of a theme is thus fundamentally holistic and is a useful analogy for the kind of holistic grasp of a manifold as constituting a unity that is required for the formation of concepts. For a helpful discussion of Kant's account of qualitative unity and its relation to concept formation and the OSUA, see Zinkin, 'The Unity of a Theme'.
} 
purported part-to-whole nature of synthesis. While there is a sense in which it is obviously correct to say that synthesis proceeds from parts to whole, in that it involves the 'running through and gathering together' of the manifold of intuition, there is nevertheless an aspect of the consciousness involved in all acts of synthesis that has a whole-part priority, in that any act of synthesis involves the consciousness of the fundamental unity of consciousness (and thus of experience) with respect to which any particular determination must be made. This is what Kant means when he writes in $\$ 26$ that the:

unity of the synthesis of the manifold, outside or within us, hence also combination with which everything that is to be represented as determined in space or time must agree, is already given a priori, along with (not in) these intuitions, as condition of the synthesis of all apprehension.

We cannot make sense of any act of figurative synthesis (whether pure or as the form of apprehension), without at the same time appealing to the holistic consciousness that accompanies this act, precisely because any act of figurative synthesis is an act of determining a region of space or time with respect to a single spatio-temporal framework. To use one of Kant's examples from $\$ 26$, to see the two states of water (liquid, frozen) as standing in necessary temporal relation to each other requires the synthetic unity of time itself as that in which all temporal relations belong, a synthetic unity that both precedes each particular act of category-guided synthesis but which itself depends on the subject's capacity to determine temporal relations via the categories.

At this point, the reader might still want to emphasize Kant's claim in the footnote that the unity that belongs to space and time 'precedes all concepts' (B160-1n). Here we must pay careful attention to the wording of the footnote. Kant goes on to claim in the footnote that it is through synthesis that 'all concepts of space and time first become possible' (B160-1n) [eine Synthesis... durch welche alle Begriffe von Raum und Zeit möglich werden]. I want to suggest that when Kant says that the unity of formal intuition 'precedes all concepts', his point is twofold. He is reiterating that space itself is the 'ground' of concepts of space in light of his introduction of a further condition for formulating spatial concepts, namely, figurative synthesis. His claim in the footnote is not that the presupposed synthesis precedes the categories, his point is that it precedes, in the sense of being a condition for, the formation of spatial concepts. Indeed, this is just what Kant goes on to explain in the Axioms of Intuition. Schematized spatial concepts, for Kant, which are required for any kind of cognition of space, depend on the 'successive synthesis of the productive imagination in the generation of shapes' as guided by the concept of an extensive magnitude (A163/ B204). That is, spatial concepts, in order to provide cognition, must be constructed, and construction is 
an act of a priori figurative synthesis. And while we cannot construct infinite space - infinite space as the structure of all constructions is 'given' only to the subject who can construct spatial concepts.

To sum up, there are three points to make about the relationship between what I have called 'original synthesis' and figurative synthesis in \$26. First, in $\S 26$, Kant is primarily concerned with concrete acts of category-guided synthesis and how they constrain perception. A priori figurative synthesis (the synthesis of spaces and times) is the form of the empirical synthesis of apprehension. The synthesis of apprehension is always directed at particular object (e.g. a house). But - and this is the second point - Kant is also at pains to stress that any such act already presupposes the unity of consciousness and thus the necessary unity of space and time themselves. This brings us to the third point. It is in undertaking to determine space and time (via figurative synthesis) that space and time are given as unified structures. As Kant puts it in the footnote, it is when the 'understanding determines sensibility' that 'space or time are first given as intuitions' (B160-1n).

\section{Ruling-out the non-conceptualist alternative}

Recent non-conceptualists (McLear, 'Two Kinds of Unity', 90; Onof and Schulting, 'Space as Form of Intuition', 28-9) have argued that space and time as forms of intuition are already unitary infinite wholes without any contribution from or connection to the understanding. ${ }^{23}$ In order to grasp this independent unity of space and time, however, the understanding must perform acts of category-guided synthesis, thus yielding space and time as formal intuitions. $^{24}$ The crucial feature of these views is that they rely on the distinction between the unity of space and time (which they claim does not depend on the understanding) and the conditions for representing this unity (which depend on the understanding). What is particularly attractive about these views (especially that of Onof and Schulting) is that they certainly seem to accord with Kant's argument in the B-Deduction. This is because, although the original unity of space and time is non-conceptual, the understanding must grasp this unity in order to represent objects in space and time, and the grasp of this unity requires the categories (Onof and Schulting, 'Space as Form of Intuition', 28). ${ }^{25}$

\footnotetext{
${ }^{23}$ This view traces its roots to Fichant, 'L'espace est representé' and Allison, Kant's Transcendental Idealism.

${ }^{24}$ For Onof and Schulting, the unity of the formal intuition of space is 'the unity of a spatial region' ('Space as Form of Intuition', 28), while for McLear it is the unity of space and time 'as mathematically describable objects' ('Two Kinds of Unity', 89).

${ }^{25}$ Here Onof and Schulting have an advantage over McLear, who argues for a kind of objective representation that belongs to sensibility prior to any involvement by the understanding apart from mere episodic consciousness (McLear, 'Two Kinds of Unity', 101). Onof and Schulting grant that all objective representation requires the unity of apperception, which in turn requires the category-guided synthesis through which space and time are determined (29). Their view is thus a prima facie better fit with the aims of the B-Deduction.
} 
Despite this initial appeal, we should reject these views, precisely because, despite initial appearances to the contrary, they allow for the very possibility the second step of the B-Deduction is meant to rule out, namely, that empirical intuitions might have a unity that does not depend on the categories. When Kant introduces the second step of the Deduction in \$21, he writes,

In the sequel (\$26) it will be shown from the way in which the empirical intuition is given in sensibility that its unity can be none other than the one that the category prescribes to the manifold of a given intuition in general.

(B144-5, italics added)

This does not suggest that the problem is one of explaining the need for the categories in light of an independent unity of space (and time) itself, as nonconceptualist views must claim, but rather that there is a lingering possibility that must be ruled out, namely that empirical intuitions might have a kind of unity that is independent of the understanding.

We see this most clearly if we turn to Colin McLear's ('Two Kinds of Unity') account of the unity of intuition. According to McLear, the fact that the unity of space and time as all-encompassing wholes in no way depends on the understanding has important consequences for Kant's account of empirical intuitions. McLear writes, 'once the unity of forms of intuition has been conceded, it is no longer clear why all intuitions do not possess a form of unity independent of the understanding' (Two Kinds of Unity', 94). ${ }^{26}$ McLear draws the same distinction that Onof and Schulting employ: the distinction between unity and the conditions for representing unity:

Kant's argument for the legitimacy of the a priori categories is broadly compatible with an interpretation of the Transcendental Deduction that does not make the unity of intuition as a form of objective representation dependent on categorical synthesis. The categories make possible the having of complex representations, which govern our grasp of the objects given through intuition, but they need not be understood as making possible our fundamental cognitive connection to the world via intuition.

('Space as Form of Intuition', 103)

In this passage, McLear is relying on the distinction between occurrences of unsynthesized intuitions, which he counts as a form of objective representation even though it involves merely the episodic consciousness of the manifest sensory qualities of objects, and the perception of objects which results from the synthesis of intuitions into the representation of complex entities that are the bearers of properties. But this strategy fails. As soon as we grant that unsynthesized intuitions are objective representations then Kant's would not be entitled to claim in the Deduction that the categories apply to all objects of the senses. This is not to deny that intuitions provide

\footnotetext{
${ }^{26} \mathrm{Grüne}$, 'Sensible Synthesis' persuasively argues that McLear conflates two different senses of 'pure intuition' in his argument.
} 
us with a 'fundamental cognitive connection to the world' which concepts alone cannot secure. It is, however, to deny that we can make sense of this connection in the absence of conceptual capacities.

Some might think that non-conceptualists have an adequate response to this. The purported response is that while it is true that the categories are required for the perceptual representation of objects, in a strong sense, that is, as complex representations with general features, the non-conceptualist is concerned with a weaker sense of 'object', namely distinct located particulars. ${ }^{27}$ Moreover, Kant need only show that the categories are required for the stronger sense of object in order to respond to the Humean challenge.

But why call this 'objective' representation? Part of what is involved in referring to intuitive states as 'objective' is that they can serve as the tribunal of beliefs and judgements. Either these states are at the level of consciousness required for objectivity - in which case the usual worry about the goal of the Deduction kicks in - or they are not. But if they are not, then they hardly seem worthy of the title 'objective'.

It is not so much that conceptualists claim that the categories are required for the representation of mere particulars, it is that the conceptualist denies that it makes sense to appeal to mere particulars on the Kantian account. When conceptualists deny that we could have intuitions in the absence of conceptual capacities, this is on the understanding of intuitions as a species of objective representation. We can, of course, stipulate that by 'intuition' we mean the contribution of sensibility prior to the synthesis of apprehension, and thus prior to consciousness. But what the conceptualist wants to say is that such a representation is not an objective representation. This is not just to say that it has not yet been brought under all of the categories (it is not yet conceived of as a substance in causal interaction with other substances, etc.), but that such a representation lacks objective purport altogether (i.e. it does not present a content to the subject). It is, after all, prior to consciousness. Why think distinct particulars, in the non-conceptualist sense, are the sort of thing Kant is at all interested in?

Here is one possible reply to the above question: Kant seems to grant that animals are conscious of distinct particulars. Do I want to deny, for example, that a dog can be aware of a shape, like a circle or a square? Yes and no. Dogs can be taught to behaviourally discriminate between things that we would describe as circular or rectangular. But part of what is going on when we perceive such objects is that we are (at least implicitly) aware of the form of the objects; this, indeed, is what makes geometry possible for Kant and furthermore, is why even the imperfect empirical drawings on a chalkboard can be used to demonstrate a priori geometric proofs. In geometry, we are not

\footnotetext{
${ }^{27}$ See Allais, 'Transcendental Idealism' and Golob, 'Why the Transcendental Deduction' for this line of response.
} 
bringing something empirical under concepts, which is what the non-conceptualists would have to claim on their account of animal (and human) intuition. Instead, that which we are consciously aware of in perception, for Kant - when it has, for example, shape - is always already suitable for generating geometrical judgements. It is only when the form of our intuitions interacts with the categories that it gets metrical structure and thus becomes the sort of thing from which a priori truths can flow.

Unlike McLear, Onof and Schulting are not primarily interested in arguing for a pre-categorial unity of empirical intuitions, but insofar as they argue for the independent unicity of space, it is not clear what blocks the move that McLear makes from this unicity to the pre-categorial unity of empirical intuitions and the resulting problem.

The conceptualist position I have defended, according to which the original unity of space and time is a result of the synthesis of sensibility and understanding, avoids this problem. This is because the unity of space and time can only be realized in conjunction with self-consciousness. We can grant that the categories do not generate or produce the unity of space and time. But, pace the non-conceptualist, we must insist that that this unity only arises in the context of self-consciousness and its categorial conditions.

\section{Acknowledgements}

I would like to thank R. Lanier Anderson, Graciela De Pierris, Michael Friedman, Hyoung Sung Kim, Dustin King, Rebecca Kukla, James Messina, Daniel Sutherland and Eric Winsberg for their detailed comments on previous drafts of this paper. Earlier versions were also presented at the 2015 Pacific APA in Vancouver, the third Biennual meeting of the North American Kant Society in Emory, and to the Philosophy Department at the University of South Florida. I am grateful to audience members for questions and comments on these occasions. I would also like to thank three anonymous referees for comments that greatly improved the paper.

\section{Bibliography}

Allais, L. 'Kant, Non-conceptual Content and the Representation of Space'. Journal of the History of Philosophy 47, no. 3 (2009): 383-413.

Allais, L. "Transcendental Idealism and the Transcendental Deduction". In Kant's Idealism: New Interpretations of a Controversial Doctrine, edited by Dennis Schulting and Jacco Verburgt, 91-107. Dordrecht: Springer, 2011.

Allison, H. E. The Kant-Eberhard Controversy. Baltimore, MD: Johns Hopkins University Press, 1973.

Allison, H. E. 'Where Have All the Categories Gone? Reflections on Longuenesse's Reading of Kant's Transcendental Deduction'. Inquiry 43, no. 1 (2000): 67-80.

Allison, H. E. Kant's Transcendental Idealism. New Haven, CT: Yale, 2004.

Anderson, R. L. 'The Wolffian Paradigm and Its Discontents: Kant's Containment Definition of Analyticity in Its Historical Context'. Archive für Geschichte der Philosophie 87, no. 1 (2005): 22-74. 
Anderson, R. L. The Poverty of Conceptual Truth: Kant's Analytic/Synthetic Distinction and the Limits of Metaphysics. Oxford: Oxford University Press, 2015.

Bauer, N. 'A Peculiar Intuition: Kant's Conceptualist Account of Intuition'. Inquiry: An Interdisciplinary Journal of Philosophy 55, no. 3 (2012): 215-37.

Brook, A. Kant and the Mind. Cambridge: Cambridge University Press, 1994.

Evans, G. Varieties of Reference. Oxford: Oxford University Press, 1982.

Falkenstein, L. Kant's Intuitionism: A Commentary on the Transcendental Aesthetic. Toronto: University of Toronto Press, 1995.

Fichant, M. '“''espace est representé comme une grandeur infinie donnée": La radicalité de l'esthétique'. Philosophie 56 (1997): 20-48.

Friedman, M. 'Kant on Geometry and Spatial Intuition'. Synthese 186 (2012): 231-55.

Friedman, M. "Space and Geometry in the B-Deduction". In Kant's Philosophy of Mathematics, Vo1. 1: The Critical Philosophy and its Background, edited by C. Posey and O. Rechter. Cambridge: Cambridge University Press, forthcoming.

Ginsborg, H. 'Was Kant a Non-Conceptualist?' Philosophical Studies 137 (2008): 65-77.

Golob, Sacha. "Why the Transcendental Deduction is Compatible with Nonconceptualism". In Kantian Nonconceptualism, edited by D. Schulting, 27-52. London: Palgrave-Macmillan, 2016.

Gomes, A. 'Is Kant's Transcendental Deduction of the Categories Fit for Purpose?' Kantian Review 15, no. 2 (2010): 118-37.

Griffith, A. 'Perception and the Categories: A Conceptualist Reading of Kant's Critique of Pure Reason'. European Journal of Philosophy 20, no. 2 (2012): 193-222.

Grüne, S. 'Sensible Synthesis and the Intuition of Space'. Proceedings of the 12th International Kant Congress, Walter de Gruyter, forthcoming.

Hanna, R. 'Kant and Nonconceptual Content'. European Journal of Philosophy 13, no. 2 (2005): 247-90.

Hegel, G. W. F. Faith and Knowledge. Translated by W. Cerf and H. S. Harris. Albany, NY: SUNY Press, 1977 [1802].

Heidegger, M. Phänomenologische Interpretation von Kant's Kritik der reinen Vernunft. Frankfurt am Main: Klostermann; translated as Phenomenological Interpretation of Kant's Critique of Pure Reason. Bloomington: Indiana University Press, 1997.

Henrich, D. 'The Proof-Structure of Kant's Transcendental Deduction'. Review of Metaphysics 22, no. 4 (1969): 640-59.

Kant, I. Gesammelte Schriften. Edited by the Prussion (later: German) Academy of Sciences. Berlin: De Gruyter, 1900.

Kant, I. Critique of Pure Reason. Translated by P. Guyer and A. Wood. Cambridge: Cambridge University Press, 1997.

Kant, I. Notes and Fragments. Edited by Paul Guyer and translated by C. Bowman, P. Guyer, and F. Rauscher. Cambridge: Cambridge University Press, 2005.

Keller, P. Kant and the Demands of Self-consciousness. Cambridge: Cambridge University Press, 1998.

Kitcher, P. 'Connecting Intuitions and Concepts at B160n'. The Southern Journal of Philosophy XXV, Supplement (1986): 137-49.

Longuenesse, B. Kant and the Capacity to Judge. Translated by Charles T. Wolfe. Princeton, NJ: Princeton University Press, 1998.

Longuenesse, B. Kant on the Human Standpoint. Cambridge: Cambridge University Press, 2005.

McDowell, J. Having the World in View: Essays on Kant, Hegel, and Sellars. Cambridge: Harvard University Press, 2009. 
McLear, C. 'Two Kinds of Unity in the Critique of Pure Reason'. Journal of the History of Philosophy 53, no. 1 (2015): 79-110.

Messina, J. 'Kant on the Unity of Space and the Synthetic Unity of Apperception'. KantStudien 105, no. 1 (2014): 5-40.

Newton, A. 'Kant on the Logical Origin of Concepts'. European Journal of Philosophy 23, no. 3 (2012): 456-84. doi:10.1111/j.1468-0378.2012.00545.x.

Onof, C., and D. Schulting. 'Kant, Kästner, and the Distinction Between Metaphysical and Geometrical Space'. Kantian Review 19, no. 2 (2014): 285-304.

Onof, C., and D. Schulting. 'Space as Form of Intuition and as Formal Intuition: On the Note to B160 in Kant's Critique of Pure Reason'. Philosophical Review 124, no. 1 (2015): 1-58.

Paton, H. J. Kant's Metaphysics of Experience: Vol 1. London: Allen \& Unwin, 1936.

Pollok, K. "'An Almost Single Inference"-Kant's Deduction of the Categories Reconsidered'. Archiv für Geschichte der Philosophie 90, no. 3 (2008): 323-45.

Sassen, B, ed. Kant's Early Critics: The Empiricist Critique of the Theoretical Philosophy. Cambridge: Cambridge University Press, 2000.

Smyth, D. 'Infinity and Givenness: Kant on the Intuitive Origin of Spatial Representation'. Canadian Journal of Philosophy 44, no. 5-6 (2014): 551-79.

Sutherland, Daniel. 2004. 'The Role of Magnitude in Kant's Critical Philosophy'. Canadian Journal of Philosophy 34, no. 3 (2004): 411-41.

Van Cleve, J. Problems from Kant. New York: Oxford University Press, 1999.

Waxman, W. Kant's Model of the Mind. Oxford: Oxford University Press, 1991.

Zinkin, M. 'The Unity of a Theme: The Subject of Judgments of Taste'. British Journal for the History of Philosophy 14, no. 3 (2006): 469-88. 